\title{
THE HEALTH IMPACT OF SAHARAN DUST EXPOSURE
}

\author{
MICHAIL KOTSYFAKIS ${ }^{1,2}$, SOTIRIOS G. ZAROGIANNIS ${ }^{3}$, and EVRIDIKI PATELAROU ${ }^{2}$ \\ ${ }^{1}$ Czech Academy of Sciences, Ceske Budejovice (Budweis), Czech Republic \\ Biology Center, Institute of Parasitology \\ ${ }^{2}$ Hellenic Mediterranean University, Heraklion, Greece \\ Nursing Department \\ ${ }^{3}$ University of Thessaly, Larissa, Greece \\ Faculty of Medicine, Department of Physiology
}

\begin{abstract}
Air pollution is a high priority global health concern. The health damaging effects of ambient particulate matter (PM), a component of air pollution, are extensively documented, with $1.4 \%$ of deaths worldwide resulting from exposure to PM. A growing body of evidence suggests that mineral dust, found in PM, may contribute to some of these deleterious health impacts. Approximately half of atmospheric mineral dust originates from the Sahara Desert. This systematic but concise review summarizes the findings from recent literature exploring the adverse health effects of Saharan dust particles worldwide. The authors have shown that 1) PM contributes to all-cause and cause-specific mortality and morbidity; 2) the PM arising from Saharan dust contributes to excess all-cause and cause-specific mortality and morbidity; and 3) larger particle sizes may be more harmful than smaller particle sizes. However, there remain many questions regarding their effects on vulnerable patient populations, underlying mechanisms of action, and regional variations in both environmental and health effects. This review highlights the urgent need for continued and deeper analyses of this emerging public health issue. Int J Occup Med Environ Health. 2019;32(6):749-60
\end{abstract}

Key words:

air pollution, particulate matter, public health, dust, Africa, Northern Africa

\section{INTRODUCTION}

The World Health Organization (WHO) regards air pollution as a top global health priority [1]. The adverse effects of particulate matter (PM), a component of air pollution, on human health are well documented. The WHO estimates that $1.4 \%$ of all deaths worldwide result from exposure to PM [2]. One of the components of PM, atmospheric mineral dust, has recently attracted attention since it may be responsible for some of the hazardous effects of PM [3].
The main source of atmospheric mineral dust is from the desert, with approximately half originating from the Sahara Desert [3], although dust also spreads from other regions including the Arabian Peninsula, Central Asia, China, Australia, America, and South Africa. Each year, 1-3 gigatons of dust are emitted from these regions [4]. Sand and dust storms frequently occur in semi-arid and arid climates. Thunderstorms and cyclones produce strong pressure gradients that increase the wind speed. The wind

\footnotetext{
Funding: this work was supported by the Grant Agency of the Czech Republic (grant No. 19-382 07247S entitled "The functional characterization of tick salivary immunomodulators belonging to the Iristatin family," grant manager: Renata Novotna) and by ERD Funds (project No. 384 CZ.01.1.01/0.0/0.0/16_019/0000759 entitled "Centre for research of pathogenicity and virulence of parasites," project manager: Lenka Pachmanova).

Received: April 16, 2019. Accepted: July 16, 2019.

Corresponding author: Michail Kotsyfakis, Czech Academy of Sciences, Biology Center, Institute of Parasitology, Branisovska 31, 370005 Ceske Budejovice (Budweis), Czech Republic (e-mail: mich_kotsyfakis@yahoo.com).
} 
then lifts and disperses large amounts of sand and dust from the soil into the atmosphere. This dust can spread several thousand kilometers from its origin. Sometimes, precipitation clears atmospheric dust, leading to wet rather than dry deposits of dispersed dust. Therefore, climatic conditions play a significant role in desert dust movement. Since vegetation can protect the ground from erosion during storms, droughts and comparable environmental conditions may contribute to the development of dust storms [4].

The Sahara Desert disperses dust worldwide, with 12\% travelling north to Europe, 28\% west to America, and $60 \%$ south to the Gulf of Guinea [3]. Saharan dust then contributes to PM levels exceeding the threshold limits established by the European Union (EU) and WHO [3]. Almost 4 million tons of desert dust from the Sahara are transported to Mediterranean regions, leading to high PM levels. Notably, during Saharan dust events, the mineral dust concentrations in PM increase by $35 \%$, and PM concentrations are increased in general. One study showed that of 6 exceedances of the EU threshold limits in a 6-month period, 5 occurred during Saharan dust days [5].

Due to the potential health impact of its dispersal, the deleterious effect of atmospheric dust is now emerging as a global health concern. As a result, there has been increasing interest in the role of Saharan dust dispersion on health over the last 2 decades [2]. Several theories on how Saharan dust impacts on human health have been proposed. Given that Saharan dust is a component of PM, it is respirable, so it could potentially increase the risk of respiratory and related illnesses and, in consequence, related cause-specific and total mortality. Additionally, Saharan dust dispersion has been linked to the transport of various micro-organisms, so it may also cause infectious diseases [2,3].

In this short review, the authors have summarized the findings presented in recent literature exploring the as- sociation between Saharan dust particles and human health, with a view to collating the available evidence and establishing areas of research that require further effort in order to better understand and eventually tackle this important domain.

\section{METHODS}

The Preferred Reporting Items for Systematic Reviews and Meta-Analyses (PRISMA) guidelines were followed [6]. The authors searched the PubMed database using the terms "Saharan dust" OR "desert dust" AND "health." Studies selected for this review (after removing duplicates) were limited to those conducted on humans and written in English, and the final search took place on May 20, 2019. The search scheme is presented in Figure 1.

\section{RESULTS}

Nineteen studies specifically investigated the health impacts of Saharan dust exposure on human health, as summarized in Table 1. Of these, 17 examined populations in Southern Europe, specifically in the Mediterranean basin, which experiences proven increases in the ambient PM levels recorded in air quality monitoring networks from Saharan dust, due to proximity to the Sahara and atmospheric dynamics [7]. Two studies focused on Caribbean populations [8,9]. All studies were epidemiological studies using a mixture of analytical techniques but mainly timeseries analyses. Primary endpoints were mainly all-cause mortality or cause-specific (cardio-respiratory) mortality, or, for those studies examining emergency admissions to hospital, either hospital admission rates [10-14] or asthma attacks [8,9]. Since the effects of air-borne particles are related to their chemical composition and size, some studies investigated associations between health outcomes and different particle sizes but all studies included the coarse fraction (i.e., PM between 2.5 and $10 \mu \mathrm{m}, \mathrm{PM}_{10-2.5}$ ). The results can be summarized as follows. First, in general, PM levels were associated with an increased risk of all- 


\section{氱
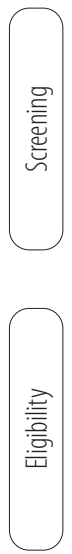

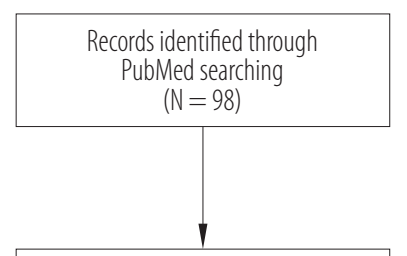

Records after duplicates/
non-English texts removed $(\mathrm{N}=98)$

Records excluded because they had no relevance

in the clinic/human health $(\mathrm{N}=75)$ $(N=2)$

Figure 1. PRISMA flow diagram for the literature search (1966-2019) regarding the health effects of dust exposure

cause and cause-specific mortality, whether of desert or non-desert origin [11,12,15-19]. In the studies examining hospital admissions or disease-specific outcomes, a similar trend was seen, with increased PM concentrations associated with increased numbers of hospitalizations $[10,12]$ or hospital-treated asthma attacks [8,9]. Therefore, PM levels, whether of desert or non-desert origin, appear to have an impact on general and respiratory health.

Second, most but not all studies detected effects on outcomes attributable to the Saharan dust component of the detected PM. These effects tended to be stronger for cause-specific outcomes, i.e., those related to cardiovascular and respiratory morbidity. For example, Trianti et al. [13] observed that desert dust days were associated with higher numbers of ER visits for asthma, chronic obstructive pulmonary disease and respiratory infections, with increases of $38 \%, 57 \%$ and $60 \%$, respectively ( $p<0.001$ ), while Staffoggia et al. [12] detected similar associations of mortality and hospitalizations with increases in desert and non-desert $\mathrm{PM}_{10}$, but stronger associations with desert dust for cardiovascular mortality (1.10\%, 95\% CI: 0.16-2.06 compared with 0.49\%; 95\% CI: 0.31-1.29 for non-desert dust).

Similarly, Reyes et al. [11] reported that while periods without Saharan dust intrusions were marked by a statistically significant association between daily mean $\mathrm{PM}_{2.5}$ concentrations, and all- and circulatory-cause hospital admissions, periods with such intrusions saw a significant 


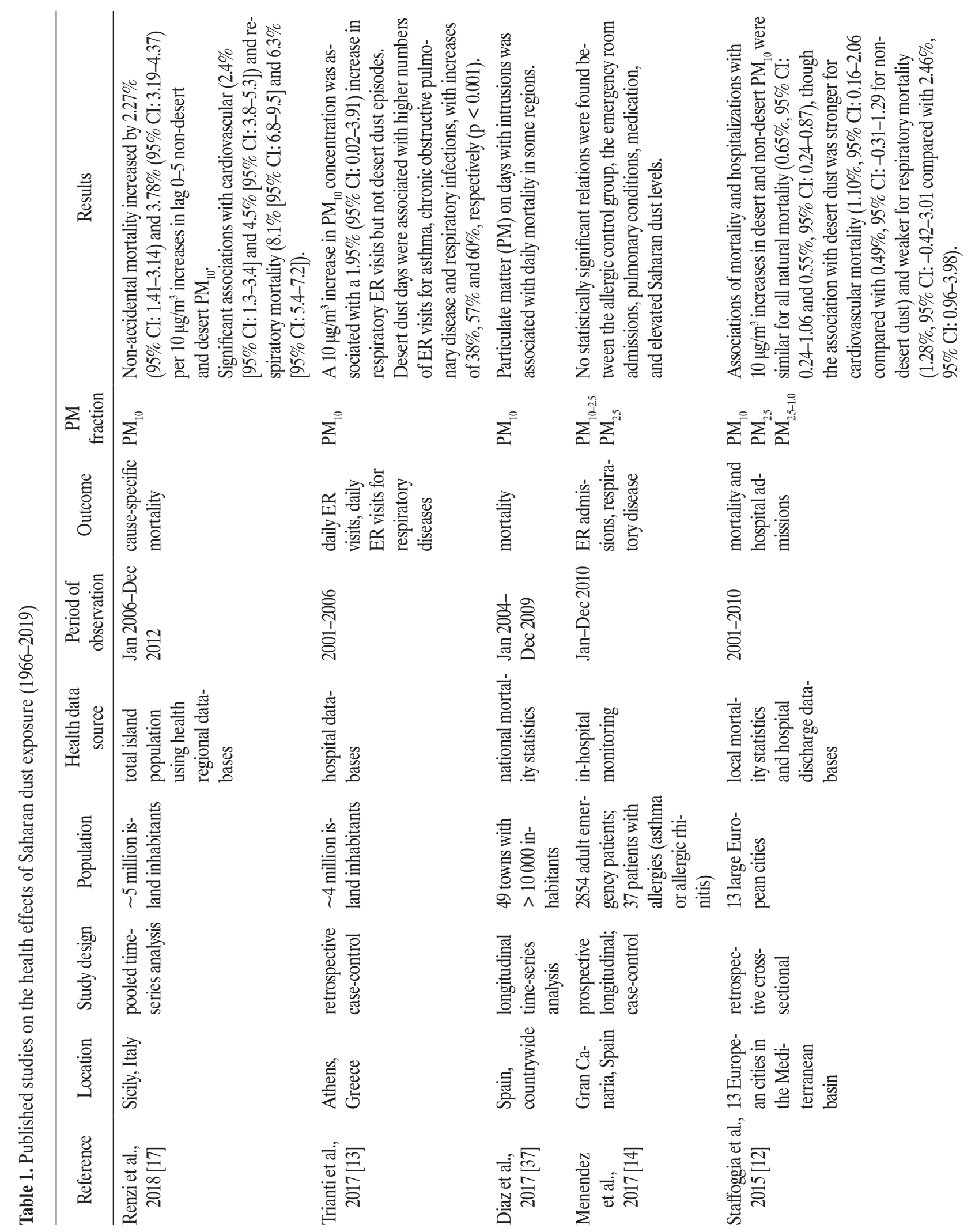



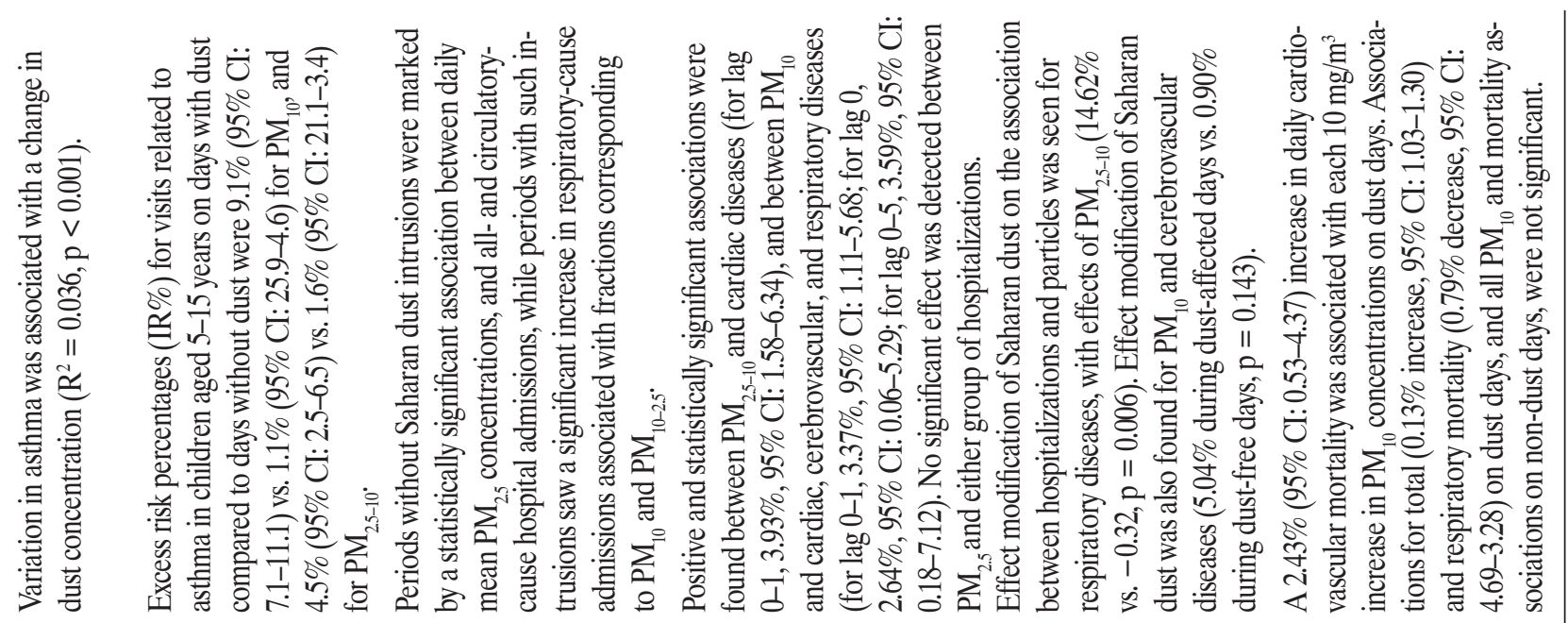

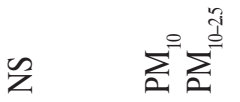

$\sum^{0} \sum^{0} \sum^{n}$

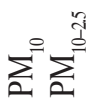

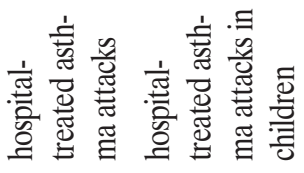
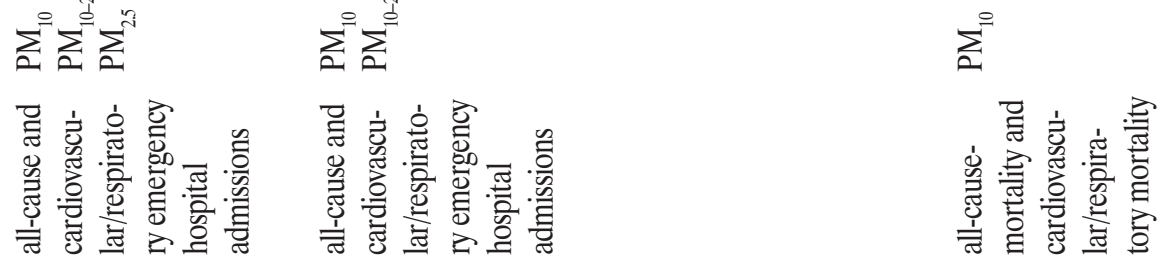

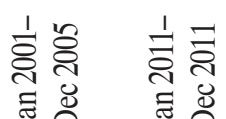

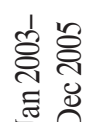

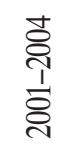

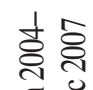

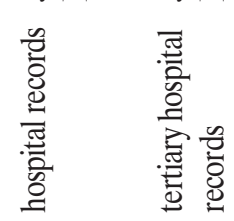

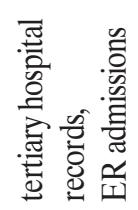

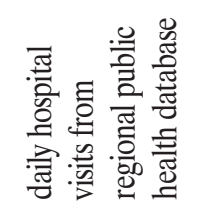

్ㅗำ

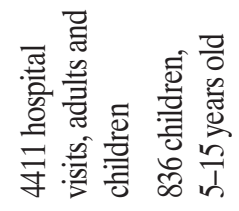

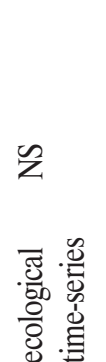

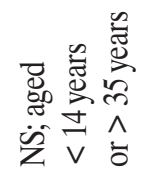
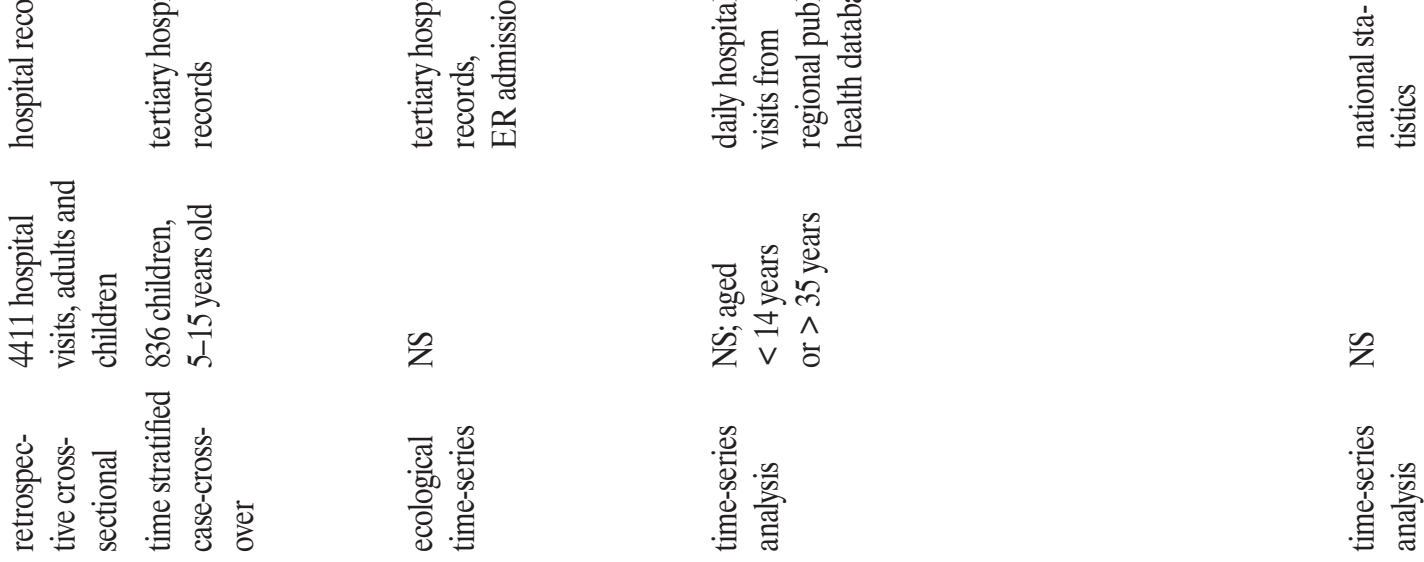

z

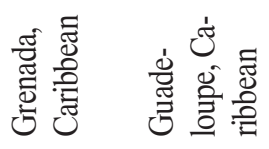

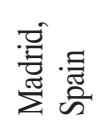

昰

.0.0

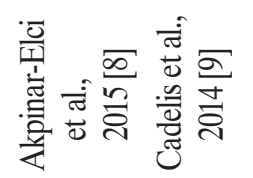

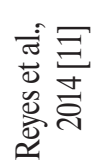

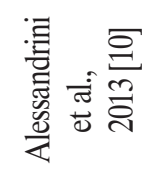

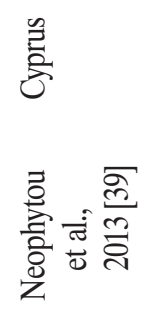




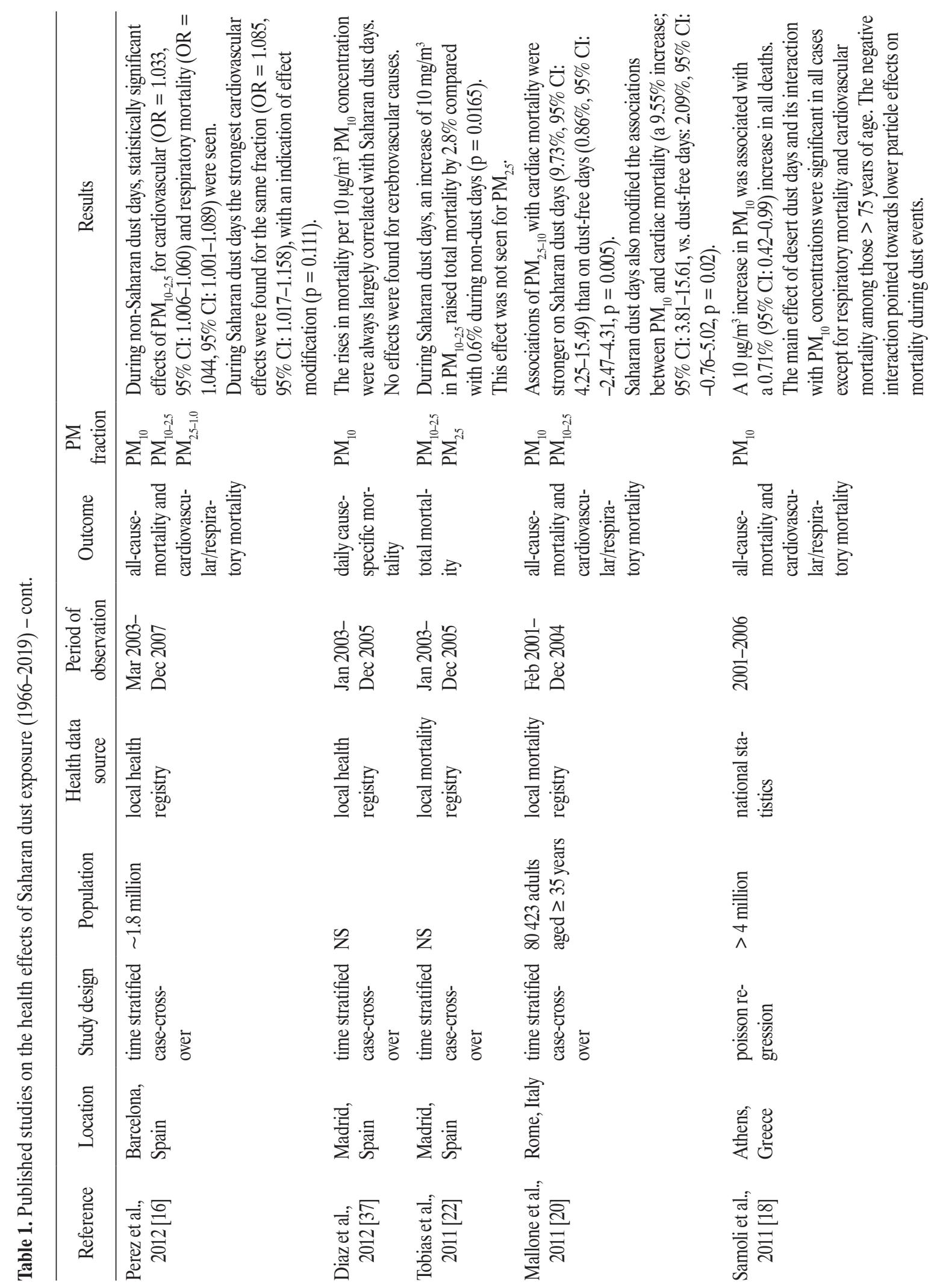




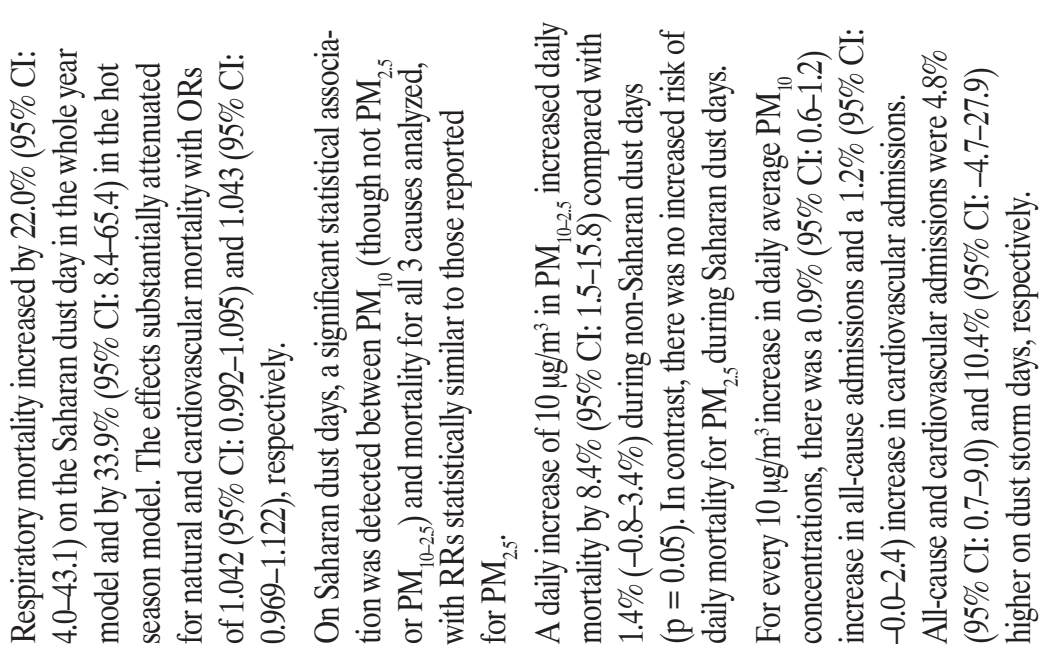

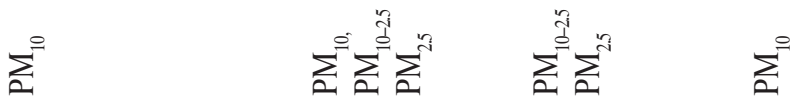
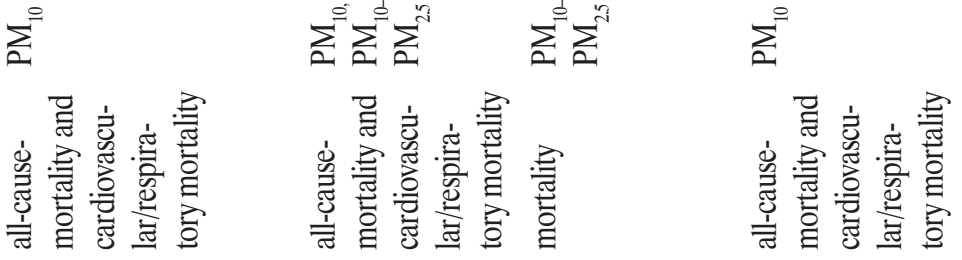

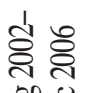

然菦

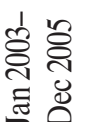

突

ڤั

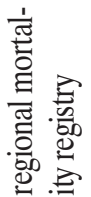<smiles>C1CC1C1CC1</smiles>

胥

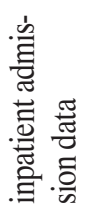

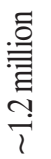

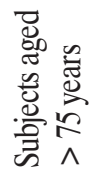

च

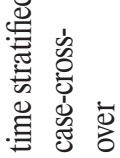

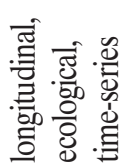

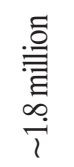

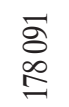

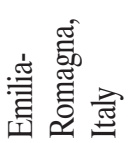<smiles>C=C[SiH2]C</smiles>

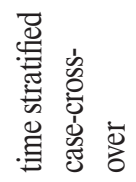

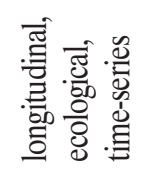

莺

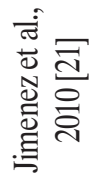

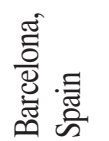

亮

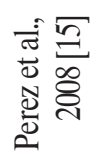

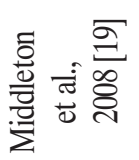

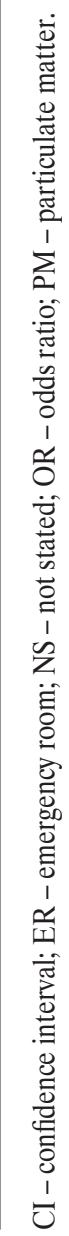


increase in respiratory-cause admissions, associated with fractions corresponding to $\mathrm{PM}_{10}$ and $\mathrm{PM}_{10-2.5}$. Alessandrini et al. [10] saw an effect modification of Saharan dust on the association between hospitalizations and particles for respiratory diseases and cerebrovascular diseases. Perez et al. [16], Mallone et al. [20], and Middleton et al. [19] in particular detected an excess risk of cardiovascular events on Saharan dust days compared to non-dust days. In a study of children admitted with asthma in Guadeloupe, Caribbean [9], there were excess risk percentages for visits related to asthma on days with dust compared to days without dust $(9.1 \%$ [95\% CI: 7.1-11.1] vs. $1.1 \%$ [95\% CI: 25.9-4.6] for $\mathrm{PM}_{10}$, and 4.5\% [95\% CI 2.5-6.5] vs. $1.6 \%$ [95\% CI 21.1-3.4] for $\left.\mathrm{PM}_{2.5-10}\right)$. However, these results were not consistent, with Samoli et al. [18] detecting a negative correlation between particle effects and mortality during dust events. Nevertheless, most of the available evidence appears to suggest that PM composed of Saharan dust contributes to excess adverse health outcomes. The third major observation from the collated studies is that particle size has an impact on the observed health effects. Several studies observed significant impacts on all-cause or cause-specific mortality for $\mathrm{PM}_{10}$ (but not $\mathrm{PM}_{2.5}$ or $\mathrm{PM}_{10-2.5}$ [21]) and $\mathrm{PM}_{10-2.5}$ (but not $\mathrm{PM}_{2.5}[15,22]$ ). Coarser particle sizes appear to have a greater impact on mortality than smaller particle sizes.

However, not all studies have reported the same pattern of findings. In individuals living in Gran Canaria Island, Spain, elevated Saharan dust levels did not exacerbate allergies in adult and elderly patients, as assessed by the number of ER admissions, medication needs, and pulmonary function [14].

\section{CONCLUSIONS}

There are several theories on the mechanism underlying the impact of Saharan dust on human health. As a component of PM, dust particles may be inhaled. Accordingly, the particle size has been proposed as a determinant of the potential of Saharan dust to cause health-related damage. Particles $>10 \mu \mathrm{m}$ are generally not respirable, so the deleterious impacts of very coarse particles are likely to be external, for example, by irritating the skin and eyes. Particles $<10 \mu \mathrm{m}\left(\mathrm{PM}_{10}\right)$ in diameter, however, can be inhaled [4] and are, therefore, associated with respiratory disorders, given their direct contact with the upper respiratory tract. The smallest particles may enter the lower respiratory tract and eventually the bloodstream, thereby exerting lower respiratory and cardiovascular effects.

Details of the molecular and cellular events underlying the interaction of these particles with physiological systems are scarce. Non-desert dust particulate matter and other air pollutants are known to cause molecular and cellular alterations, for example, aberrant gene expression from exposure to particulate matter in general and anthropogenic pollutants specifically [23-26]. Such testing began at the bench using animal models and is now entering the clinical domain. Understanding how desert dust exposure interacts with specific tissues and cell populations at the molecular level could shed light on other health-damaging effects of dust exposure, deepen our knowledge of dust exposure beyond the effects based on the particle size, and provide opportunities for predictive tests or exposure biomarkers.

An interesting hypothesis is that infectious diseases disseminated through dust dispersion may also be responsible for adverse health effects. One way in which this might occur is that dust inhalation may damage protective mucosae, rendering individuals susceptible to bacterial infection [4]. Microbial populations and anthropogenic pollutants have been shown to travel on dust [3] and may contribute to outbreaks of infectious diseases such as meningitis [27], and some studies support this theory [28,29].

One study compared the atmospheric microbiome on dust-affected and dust-free days by applying modern ge- 
nomic techniques to investigate the impact of dust storms on the airborne microbial community [30]. Their results showed that the relative abundance of desert soil-associated bacteria increased during dust events, while the relative abundance of anthropogenic-influenced taxa decreased. Accordingly, they concluded that dust storms enrich the ambient airborne microbiome with new soil-derived bacteria that disappear as the dust settles, suggesting that the bacteria are transported attached to dust particles [30]. Similarly, recent investigations of the desert dust composition suggest that toxic waste may be transported through the movement of desert dust [31-33]. Given that environmental regulations between countries from which the dust originates and the countries to which it is transported may significantly differ, this may present a fertile area of research, with a significant impact on public policy and air quality standards [20].

An analysis of the microbial content of a Saharan dust event in Italy showed the contamination of local soil with desert dust microorganisms, supporting the hypothesis that dust storms can move microbial communities from their origin to new environments [27]. Accordingly, 2 recent studies have linked infectious disease occurrence, specifically meningitis, to Saharan dust movements. Diokhane et al. [29] conducted a study during winter and spring 2012 in Dakar, Senegal, which is part of the Sahelian zone, also referred to as the "meningitis belt." The number of meningitis cases was 3-times higher during this period compared to the same season in 2013. Notably, their investigation evidenced higher PM concentrations as well as elevated atmospheric dust loading during the period of increased meningitis cases. Perez Garcia-Pando et al. [34] analyzed wind and dust information alongside seasonal incidences of meningitis in Niger, and reported that these environmental conditions might predict meningitis outbreaks. In contrast, Woringer et al. [28] could not identify any association between epidemic meningitis in the "meningitis belt" and atmospheric dust load.
Finally, Skonieczny et al. [35] recently reconstructed Saharan dust deposition > 240000 years and in doing so demonstrated that present-day Saharan dust deposition is elevated compared to 5000-11 000 years ago. During that time, decreased dust in Saharan plumes may have contributed to the development of monsoon rains, and the effect of dust may continue to impact on climatic change [35]. An in-depth understanding of Saharan dust deposition, its environmental impact, and its health-related sequelae may not only be relevant but also increasingly urgent as both a public health and environmental concern.

In collating the available evidence in this mini-review, the authors have shown that 1) PM contributes to allcause and cause-specific mortality and morbidity; 2) the PM arising from Saharan dust contributes to excess allcause and cause-specific mortality and morbidity; and 3) larger particle sizes may be more harmful than smaller particle sizes. Several associations exist between Saharan dust exposure and adverse health outcomes. As a PM component, Saharan dust is respirable and, as expected [2,3], reportedly increases respiratory hospitalizations in patients with asthma, allergic disorders, and other respiratory diseases [8-11,16,36,37]. The theorized association with cardiovascular illness [4] has been demonstrated in a subset of studies that show an increase in mortality due to cardiovascular causes upon dust exposure [20,21,38]. While the evidence supporting a health impact of Saharan dust exposure is emerging and fairly robust, the mechanisms underlying these associations remain elusive and require further study, perhaps by assessing blood-borne molecules, such as through gene expression or metabolite analyses, on Saharan dust days.

\section{ACKNOWLEDGMENTS}

The authors would like to acknowledge Dr. Sunali Wadehra and Wadehra Medical Writing, LLC and Nextgenediting (www.nextgenediting.com) for providing editorial support services. 


\section{REFERENCES}

1. World Health Organization [Internet]. Geneva: The Organization; 2016 [cited 2019 Apr 24]. Ambient Air Pollution: A global assessment of exposure and burden of disease. Available from: https://www.who.int/phe/publications/air-pollution-globalassessment/en/.

2. Venero-Fernandez SJ. Saharan Dust Effects on Human Health: A Challenge for Cuba's Researchers. MEDICC Rev. 2016;18(3):32-4.

3. Karanasiou A, Moreno N, Moreno T, Viana M, de Leeuw F, Querol X. Health effects from Sahara dust episodes in Europe: literature review and research gaps. Environ Int. 2012;47:107-14, https://doi.org/10.1016/j.envint.2012.06.012.

4. Terradellas SN, Xiao-Ye Zhang [Internet]. Airborne Dust: A Hazard to Human Health, Environment, and Society. Geneva: World Meteorological Organization; 2015 [cited 2019 Apr 24]. Available from: https://public.wmo.int/en/resources/bulletin/ airborne-dust-hazard-human-health-environment-and-society.

5. Vasilatou V, Diapouli E, Abatzoglou D, Bakeas EB, Scoullos M, Eleftheriadis K. Characterization of PM2.5 chemical composition at the Demokritos suburban station, in Athens Greece. The influence of Saharan dust. Environ Sci Pollut Res Int. 2017;24(12):11836-46, https://doi.org/10.1007/ s11356-017-8684-3.

6. Moher D, Liberati A, Tetzlaff J, Altman DG, Group P. Preferred reporting items for systematic reviews and meta-analyses: the PRISMA statement. PLoS Med. 2009;6(7):e1000097, https://doi.org/10.1371/journal.pmed.1000097.

7. Querol X, Pey J, Pandolfi M, Alastuey A, Cusack M, Pérez N, et al. African dust contributions to mean ambient PM10 mass-levels across the Mediterranean Basin. Atmospheric Environment. 2009;43(28):4266-77.

8. Akpinar-Elci M, Martin FE, Behr JG, Diaz R. Saharan dust, climate variability, and asthma in Grenada, the Caribbean. Int J Biometeorol. 2015;59(11):1667-71, https://doi.org/10.1007/ s00484-015-0973-2.

9. Cadelis G, Tourres R, Molinie J. Short-term effects of the particulate pollutants contained in Saharan dust on the visits of children to the emergency department due to asthmatic conditions in Guadeloupe (French Archipelago of the Caribbean). PLoS One. 2014;9(3):e91136, https://doi.org/10.1371/ journal.pone.0091136.

10. Alessandrini ER, Stafoggia M, Faustini A, Gobbi GP, Forastiere F. Saharan dust and the association between particulate matter and daily hospitalisations in Rome, Italy. Occup Environ Med. 2013;70(6):432-4, https://doi.org/10.1136/ oemed-2012-101182.

11. Reyes M, Diaz J, Tobias A, Montero JC, Linares C. Impact of Saharan dust particles on hospital admissions in Madrid (Spain). Int J Environ Health Res. 2014;24(1):63-72, https:// doi.org/10.1080/09603123.2013.782604.

12. Stafoggia M, Zauli-Sajani S, Pey J, Samoli E, Alessandrini E, Basagana X, et al. Desert Dust Outbreaks in Southern Europe: Contribution to Daily $\operatorname{PM}(1)(0)$ Concentrations and Short-Term Associations with Mortality and Hospital Admissions. Environ Health Perspect. 2016;124(4):413-9, https://doi.org/10.1289/ehp.1409164.

13. Trianti SM, Samoli E, Rodopoulou S, Katsouyanni K, Papiris SA, Karakatsani A. Desert dust outbreaks and respiratory morbidity in Athens, Greece. Environ Health. 2017;16(1):72, https://doi.org/10.1186/s12940-017-0281-x.

14. Menendez I, Derbyshire E, Carrillo T, Caballero E, Engelbrecht JP, Romero LE, et al. Saharan dust and the impact on adult and elderly allergic patients: the effect of threshold values in the northern sector of Gran Canaria, Spain. Int J Environ Health Res. 2017;27(2):144-60, https://doi.org/10. 1080/09603123.2017.1292496.

15. Perez L, Tobias A, Querol X, Kunzli N, Pey J, Alastuey A, et al. Coarse particles from Saharan dust and daily mortality. Epidemiology. 2008;19(6):800-7.

16. Perez L, Tobias A, Querol X, Pey J, Alastuey A, Diaz J, et al. Saharan dust, particulate matter and cause-specific mortality: a case-crossover study in Barcelona (Spain). Environ Int. 2012;48:150-5, https://doi.org/10.1016/j.envint.2012.07.001.

17. Renzi M, Forastiere F, Calzolari R, Cernigliaro A, Madonia G, Michelozzi P, et al. Short-term effects of desert and 
non-desert PM10 on mortality in Sicily, Italy. Environ Int. 2018;120:472-9, https://doi.org/10.1016/j.envint.2018.08.016.

18. Samoli E, Kougea E, Kassomenos P, Analitis A, Katsouyanni K. Does the presence of desert dust modify the effect of PM10 on mortality in Athens, Greece? Sci Total Environ. 2011;409(11): 2049-54, https://doi.org/10.1016/j.scitotenv.2011.02.031.

19. Middleton N, Yiallouros P, Kleanthous S, Kolokotroni O, Schwartz J, Dockery DW, et al. A 10-year time-series analysis of respiratory and cardiovascular morbidity in Nicosia, Cyprus: the effect of short-term changes in air pollution and dust storms. Environ Health. 2008;7:39, https://doi.org/ 10.1186/1476-069X-7-39.

20. Mallone S, Stafoggia M, Faustini A, Gobbi GP, Marconi A, Forastiere F. Saharan dust and associations between particulate matter and daily mortality in Rome, Italy. Environ Health Perspect. 2011;119(10):1409-14, https://doi. org/10.12989/ehp.1003026.

21. Jimenez E, Linares C, Martinez D, Diaz J. Role of Saharan dust in the relationship between particulate matter and short-term daily mortality among the elderly in Madrid (Spain). Sci Total Environ. 2010;408(23):5729-36, https:// doi.org/10.1016/j.scitotenv.2010.08.049.

22. Tobias A, Perez L, Diaz J, Linares C, Pey J, Alastruey A, et al. Short-term effects of particulate matter on total mortality during Saharan dust outbreaks: a case-crossover analysis in Madrid (Spain). Sci Total Environ. 2011;412-413:386-9, https://doi.org/10.1016/j.scitotenv.2011.10.027.

23. Vrijens K, Bollati V, Nawrot TS. MicroRNAs as potential signatures of environmental exposure or effect: a systematic review. Environ Health Perspect. 2015;123(5):399-411, https://doi.org/10.1289/ehp.1408459.

24. Lambertini L, Byun HM. Mitochondrial Epigenetics and Environmental Exposure. Curr Environ Health Rep. 2016;3(3): 214-24, https://doi.org/10.1007/s40572-016-0103-2.

25. Perduca V, Omichessan H, Baglietto L, Severi G. Mutational and epigenetic signatures in cancer tissue linked to environmental exposures and lifestyle. Curr Opin Oncol. 2018;30(1): 61-7, https://doi.org/10.1097/cco.0000000000000418.
26. Smeester L, Fry RC. Long-Term Health Effects and Underlying Biological Mechanisms of Developmental Exposure to Arsenic. Curr Environ Health Rep. 2018;5(1):134-44, https://doi.org/10.1007/s40572-018-0184-1.

27. Weil T, De Filippo C, Albanese D, Donati C, Pindo M, Pavarini $\mathrm{L}$, et al. Legal immigrants: invasion of alien microbial communities during winter occurring desert dust storms. Microbiome. 2017;5(1):32, https://doi.org/10.1186/s40168-0170249-7.

28. Woringer M, Martiny N, Porgho S, Bicaba BW, Bar-Hen A, Mueller JE. Atmospheric Dust, Early Cases, and Localized Meningitis Epidemics in the African Meningitis Belt: An Analysis Using High Spatial Resolution Data. Environ Health Perspect. 2018;126(9):97002, https://doi.org/10.1289/ ehp2752.

29. Diokhane AM, Jenkins GS, Manga N, Drame MS, Mbodji B. Linkages between observed, modeled Saharan dust loading and meningitis in Senegal during 2012 and 2013. Int J Biometeorol. 2016;60(4):557-75, https://doi.org/10.1007/ s00484-015-1051-5.

30. Mazar Y, Cytryn E, Erel Y, Rudich Y. Effect of Dust Storms on the Atmospheric Microbiome in the Eastern Mediterranean. Environ Sci Technol. 2016;50(8):4194-202, https://doi. org/10.1021/acs.est.5b06348.

31. Perrone MG, Vratolis S, Georgieva E, Torok S, Sega K, Veleva B, et al. Sources and geographic origin of particulate matter in urban areas of the Danube macro-region: The cases of Zagreb (Croatia), Budapest (Hungary) and Sofia (Bulgaria). Sci Total Environ. 2018;619-620:1515-29, https:// doi.org/10.1016/j.scitotenv.2017.11.092.

32. Fanizza C, De Berardis B, Ietto F, Soggiu ME, Schiro R, Inglessis $\mathrm{M}$, et al. Analysis of major pollutants and physico-chemical characteristics of PM2.5 at an urban site in Rome. Sci Total Environ. 2018;616-617:1457-68, https://doi. org/10.1016/j.scitotenv.2017.10.168.

33. Garrison VH, Majewski MS, Konde L, Wolf RE, Otto RD, Tsuneoka Y. Inhalable desert dust, urban emissions, and potentially biotoxic metals in urban Saharan-Sahelian air. 
Sci Total Environ. 2014;500-501:383-94, https://doi.org/10. 1016/j.scitotenv.2014.08.106.

34. Perez Garcia-Pando C, Stanton MC, Diggle PJ, Trzaska S, Miller RL, Perlwitz JP, et al. Soil dust aerosols and wind as predictors of seasonal meningitis incidence in Niger. Environ Health Perspect. 2014;122(7):679-86. https://doi.org/10. 1289/ehp.1306640.

35. Skonieczny C, McGee D, Winckler G, Bory A, Bradtmiller LI, Kinsley CW, et al. Monsoon-driven Saharan dust variability over the past 240,000 years. Sci Adv. 2019;5(1):eaav1887, https://doi.org/10.1126/sciadv.aav1887.

36. Moustris KP, Proias GT, Larissi IK, Nastos PT, Koukouletsos KV, Paliatsos AG. Health impacts due to particulate air pollution in Volos City, Greece. J Environ Sci Health A Tox Hazard Subst Environ Eng. 2016;51(1):15-20, https:// doi.org/10.1080/10934529.2015.1079099.

37. Diaz J, Tobias A, Linares C. Saharan dust and association between particulate matter and case-specific mortality: a case-crossover analysis in Madrid (Spain). Environ Health. 2012;11:11, https://doi.org/10.1186/1476-069x-11-11.
38. Diaz J, Linares C, Carmona R, Russo A, Ortiz C, Salvador P, et al. Saharan dust intrusions in Spain: Health impacts and associated synoptic conditions. Environ Res. 2017;156:45567, https://doi.org/10.1016/j.envres.2017.03.047.

39. Neophytou AM, Yiallouros P, Coull BA, Kleanthous S, Pavlou P, Pashiardis S, et al. Particulate matter concentrations during desert dust outbreaks and daily mortality in Nicosia, Cyprus. J Expo Sci Environ Epidemiol. 2013;23(3):275-80, https://doi.org/10.1038/jes.2013.10.

40. Zauli Sajani S, Miglio R, Bonasoni P, Cristofanelli P, Marinoni A, Sartini C, et al. Saharan dust and daily mortality in Emilia-Romagna (Italy). Occup Environ Med. 2011;68(6): 446-51, https://doi.org/10.1136/oem.2010.058156.

This work is available in Open Access model and licensed under a Creative Commons Attribution-NonCommercial 3.0 Poland License - http://creativecommons.org/ licenses/by-nc/3.0/pl/deed.en. 